\title{
The intricate and symbiotic relationship between educational institutions and the industry
}

Gabrielle Thériault, Stéphane Galibois

Gabrielle Thériault, Stéphane Galibois, "The intricate and symbiotic relationship between educational institutions and the industry," Proc. SPIE 11143, Fifteenth Conference on Education and Training in Optics and Photonics: ETOP 2019, 111431W (2 July 2019); doi: 10.1117/12.2523871 Photonics: ETOP 2019, 2019, Quebec City, Quebec, Canada 


\title{
The intricate and symbiotic relationship between Educational institutions and the Industry
}

\author{
Gabrielle Thériault ${ }^{*}$, Stéphane Galibois ${ }^{\mathrm{a}}$ \\ ${ }^{a}$ Gentec Electro-Optics, Inc., 445 St-Jean-Baptiste, Suite 160, Québec (QC), Canada, G2E 5N7
}

\begin{abstract}
Most Optics \& Photonics hubs face the same challenges, especially in a very competitive, near-zero unemployment rates economy: not enough trained personnel at all levels (from technicians to Ph.D. candidates), entering the workforce. To reverse this trend, it is imperative that the Industry and Educational institutions team up towards better identifying the needs of the industry, both in terms of number of graduates and of their skillsets.

The first driver of a healthy workforce is the number of graduates in related programs. Encouraging teenagers to pursue science and engineering studies is beneficial to our industry in the long term. The second driver is highly-qualified personnel. Over the years, we have identified key skills for our industry and how they can be acquired either within standard cursi or through participation and organization of extracurricular activities.

We will present two examples on how our company collaborates with educational institutions located near our headquarters to answers the challenges mentioned above. With the Photonics Games, we helped develop an optics challenge for high school students. On top of raising interest for our field, an added benefit of this event is that the student organizers acquire project-management skills that complement their studies. At the "Challenge Techno", some of our employees share their personal experience and show how careers in Optics \& Photonics can lead down varied paths, even when all starting as technicians.
\end{abstract}

These examples show that both academia and the industry can contribute to nurture and support tomorrow's workforce.

Keywords: Meeting industry needs, Training for the industry, Collaboration with academia, Key skills, Industry outreach, Tomorrow's workforce

\section{INTRODUCTION}

Today's employment market in Quebec and generally Canada, is what the real estate market was in the early 2000's: if for real estate it was a seller's market, today's employment climate is a job seeker's market. Indeed, there is more demand for skilled personnel than ever, to the point where there's a true shortage of manpower that is felt by a large spectrum of companies: from the coffee shops and convenience stores who need to cut down on opening hours, to the high tech companies, who likely will need to slow down growth with regards to actual potential of growth.

For a business owner, be it private or public, there's little more annoying than not being able to grow and capture market shares at a rate that is readily accessible not because of product potential and popularity on the market but because of the inability to develop and produce them at the level of the demand. These market shares missed today will translate into compound annual growth rate reduction which may be hard to compensate for over many years.

It is thus important that the employers and educational institutions be in sync and totally aligned with regards to skillset definition, cursus and forecasted available positions at the different professional levels: technical, undergraduate and graduate levels.

This presentation's objective is aimed at describing the current situation in Quebec in more details to provide some momentum towards promoting discussions between the industry and the educational institutions. The ultimate goal being one of, in time, establishing a modus operandi which will ensure a true modulation of the types and numbers of graduates from the different skill levels that will meet a true industry demand. This ensures better placement rates for graduating students and more efficient HR management for the companies hiring them. And this all translates into a healthier economy for the region.

*gtheriault@gentec-eo.com; phone 1-418-651-8003 ext. 330; gentec-eo.com

Fifteenth Conference on Education and Training in Optics and Photonics: ETOP 2019, edited by

Anne-Sophie Poulin-Girard, Joseph A. Shaw, Proc. of SPIE Vol. 11143, 111431W · (c) 2019

SPIE, ICO, IEEE, OSA · CCC code: 0277-786X/19/\$18 · doi: 10.1117/12.2523871

Proc. of SPIE Vol. $11143111431 \mathrm{~W}-1$ 


\section{A PORTRAIT OF THE CURRENT EMPLOYMENT SITUATION IN QUEBEC}

\subsection{How the Quebec school system works}

In the province of Quebec, there are basically 4 different diploma levels, depending on the type of studies after high school. These degrees are':

- Vocational training

- Technical training

- $\quad$ Undergraduate degree (BA)

- Graduate and postgraduate degrees $(\mathrm{MA}, \mathrm{PhD})$

These levels are illustrated in figure 1.

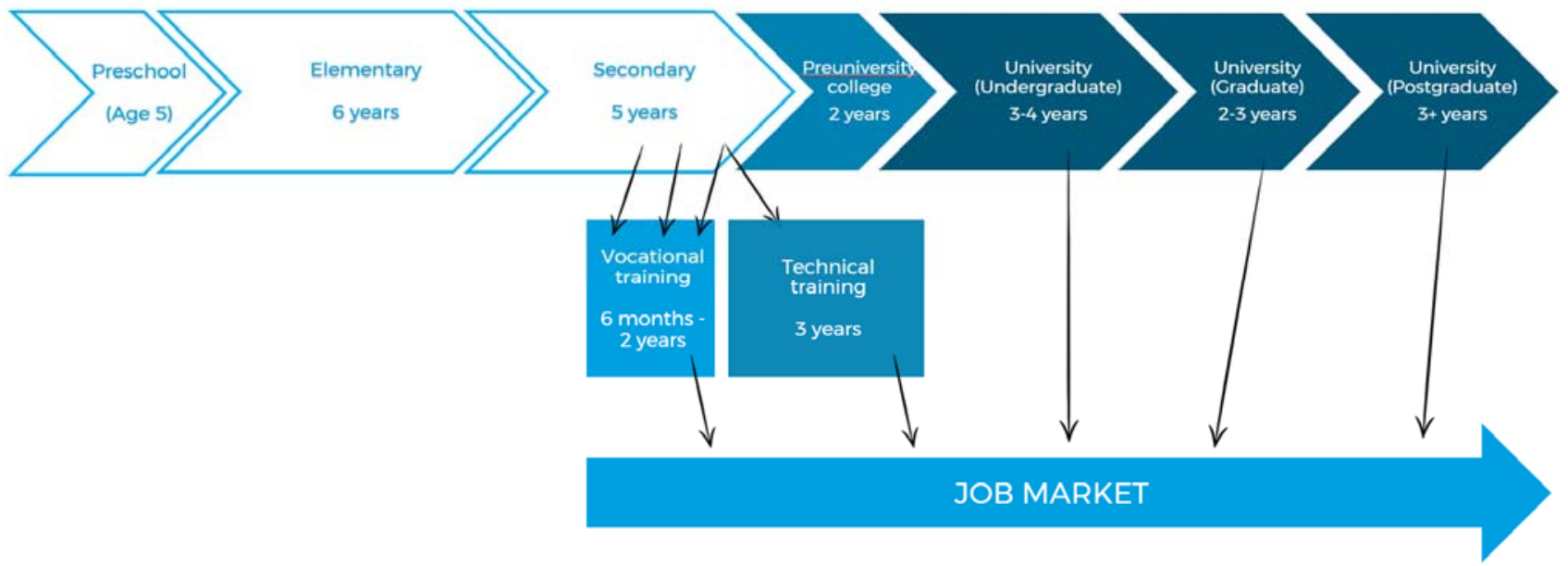

Figure 1. How to access the job market from the Quebec school system. Adapted from [1].

\subsection{Industry needs vs graduating students}

The industry of optics and photonics is generally speaking in good health, but we are currently dealing with workforce problems. The unemployment rate in Canada is at a historical low: it has been under $6 \%$ for the last year ${ }^{2}$. With so few people looking for employment, companies must rely on the school system to provide new qualified personnel.

Quebec City is an optics-photonics hub. Although our city is quite small (population of less than 1 million in the metropolitan area), it contains over 100 optics-photonics companies, which provide almost 6000 jobs directly in this field ${ }^{3}$. Companies in this hub need a qualified workforce composed mainly of people with either technical training or undergraduate and graduate degrees in programs related to optics and photonics. For example, at Gentec-EO, slightly more than half of our employees have studied either in an optics-photonics program or in a related scientific/engineering program. $57 \%$ of them have a technical training, $29 \%$ undergraduate and $14 \%$ graduate or postgraduate.

Close to Quebec City, there is only one college that offers technical training related to optics and photonics: Cégep de La Pocatière offers the technical degree called "Technologie du genie physique". This program covers both work with electronics and lasers. In the last few years, there were typically 10 to 15 graduating students per year, and these numbers have been going down. Also, almost $70 \%$ of them continue studying at the bachelor's level right after their diploma $^{4}$. This leaves a very small number of potential new employees available each year. At Gentec-EO, for example, we require this training for all employees in the optical calibration laboratory since it implies working daily with high power lasers.

The situation is much less critical when it comes to finding new employees with university-level training, since there are many different programs that can lead to employment in optics and photonics. For example, at Gentec-EO we have 
employees with the following bachelor's degrees: Physics, Physics Engineering, Software Engineering, Electrical Engineering, Mechanical Engineering and Chemistry.

The need for more technical training in the workforce is not only a problem in optics and photonics. In 2018, the Quebec government has published a 5-year plan to improve the workforce situation ${ }^{5}$. This plan includes the promotion and valorisation of trades and professions, with the objective of encouraging more students to pursue vocational and technical training.

\section{KEY SKILL SETS FOR OUR INDUSTRY BY LEVEL OF STUDIES}

The following section aims at defining what is typically required in the optics-photonics field, using the nomenclature for the different schooling levels in the province of Quebec. Also, some of the typical tasks that can be found in opticsphotonics companies.

\subsection{Technical}

- Laboratory work (with lasers and other optical devices)

- Optical calibration

- Electrical calibration

- Assembly

- Quality control

- Customer support

- Repair \& diagnostics

- Laboratory equipment maintenance

\subsection{Undergraduate}

- Project management

- Product development

- Technical validation of specifications

- Integration of technologies

- Programming (software \& firmware)

- Laboratory experiments

- Sales and market development

- Advanced technical support

\subsection{Postgraduate}

- All of the above, plus...

- New technology development (applied research)

- Technological watch

- Product portfolio management 


\section{GENTEC-EO'S INVOLVEMENT IN LOCAL INITIATIVES}

Being a small company, we could not expect to have a lot of political weight, and neither do we have the budget for organizing large-scale initiatives such as influencing regulations or national standards. But we can still get involved in our local community. In this section, we will present two examples on how our company collaborates with educational institutions located near our headquarters to answer the challenges mentioned above.

\section{1 “Jeux photoniques" (Photonic Games) at Université Laval}

The Photonic Games is a yearly event of optics-themed games and challenges for secondary school students, organized by the COPL (Center for Optics, Photonics and Lasers) students at Université Laval. This event is ongoing since 2008 and has now grown to last 2 days and the latest edition included 300 students and 90 university volunteers 6 .

Two years ago, the organizers wanted to create new challenges, and Gentec-EO decided to help out. The challenge that we helped to develop is inspired by science fiction movies such as Star Wars, where enemy ships are shot with laser beams. From a specified distance, the participants must aim a laser pointer at a Gentec-EO beam profiling camera that detects the laser's position and displays it on the computer screen. The organizers programmed a LabVIEW routine that displays moving targets and counts the times a target has been hit.

This challenge does not require specific optics skills, but while playing, the participants learn that a laser beam can be detected and tracked precisely by certain instruments. They also understand that such technologies can be created and manufactured in their home town, which can convince some of these teenagers that a technology-related career can actually be accessible to them.

On top of raising interest for our field amidst the participants, an added benefit of this event is that the student organizers (who have a high potential of joining the workforce in our industry) acquire project-management skills that complement their studies.

\section{2 “Challenge techno" at Cégep de la Pocatière}

The number of new optics \& photonics technicians entering the job market every year in our region is very low, and they all come from the same program. So, when we learned that some of the teachers in that program were organizing an event to create awareness about this program and encourage teenagers to come and visit their installations, we were happy to join the effort.

At the "Challenge Techno", secondary school students form teams to face technological challenges in both electronics and photonics ${ }^{7}$. During a quiz-based challenge, they visit booths from various local companies to learn about their technologies.

Two of our employees who have studied in "Technologie du génie physique" participated by sharing their personal experience and career path. One is now VP for Production and the other is Quality Director. This served to demonstrate that a technical degree can lead down varied paths and is definitely not limited to repetitive tasks (as it is believed in "common knowledge").

By getting involved in local events such as these, we hope to encourage more students to join study optics \& photonics, at all levels. Our involvement also has the added benefit that our company name is better known by the students, who might consider us as potential employer once they reach the job market.

\section{CONCLUSION}

It would be constructive for committees to be put together involving members of the industry, governmental agencies (MEIE, Quebec International, etc.) and all relevant levels of educational institutions. These committees would be working together to better establish current and future economic trends, such as trade and market orientations in order to define the best strategies to attract and train the future candidates to join the workforce in the best foreseeable future. With the aim of ensuring the industry isn't choked with lack of properly trained personnel and that the students are oriented towards cursus that provide for the best potential career opportunities, the committees would also work closely with the government to adapt not only the educational structure and programs but also to promote the optics-photonics field as to entice future students who are currently at lower levels of the educational system. 
An industry that is prevented from growing can but collapse and this too often results in adverse effects to the economy. The current employment situation - of more jobs than qualified personnel available - may not be easily solved in the short term but better planning for such future events can only be beneficial to our community.

\section{REFERENCES}

[1] Ministère de l'Éducation, du Loisir et du Sport, [Vocational and Technical Training in Quebec], Gouvernement du Québec, Canada, ISBN 978-2-550-59663-9 (2010).

[2] Statistics Canada, "Chart 2: Unemployment rate", 5 April 2019, https://www150.statcan.gc.ca/n1/dailyquotidien/190405/cg-a002-eng.htm (29 April 2019).

[3] Québec International, "Québec City: an innovative hub of electronics and optics-photonics", 2019, https://www.quebecinternational.ca/en/choose-quebec/quebec-industries/electronics-and-optics-photonics (29 April 2019).

[4] Cégep de La Pocatière, "Technologie du génie physique", 2019, https://www.cegeplapocatiere.qc.ca/programmes/techniques/technologie-du-genie-physique/ (29 April 2019).

[5] Gouvernement du Québec, [National workforce strategy 2018-2023], Gouvernement du Québec, Canada, ISBN 978-2-550-82334-6 (2018).

[6] Jeux Photoniques, « Jeux photoniques », 2019, http://www.repol.copl.ulaval.ca/jeux/index.php (29 April 2019).

[7] Maxime Paradis, Le Placoteux, "Une réussite pour le 1er Challenge techno du Cégep de La Pocatière", 24 October 2018, https://www.leplacoteux.com/reussite-1er-challenge-techno-cegep-de-pocatiere/ (29 Avril 2019). 